\title{
Correction to: Bioaerosol of salt chambers in the 'Wieliczka' Salt Mine, Poland
}

\author{
D. Myszkowska • M. Kostrzon - W. Dyga • J. Kędzierska • M. Namysł • \\ A. Stanisz $\cdot$ M. Zagórska $\cdot$ M. Ziemianin $\cdot$ K. Obtułowicz $\cdot$ E. Czarnobilska
}

Published online: 24 April 2019

(C) Springer Nature B.V. 2019

\section{Correction to: Aerobiologia}

https://doi.org/10.1007/s10453-019-09561-7

In the original publication of the article, the authors given and family names were swapped in the author group. The correct author group is given in this correction.

The original article has been corrected.

The original article can be found online at https://doi.org/10.1007/s10453-019-09561-7.

D. Myszkowska $(\bowtie) \cdot$ W. Dyga $\cdot$ M. Ziemianin .

K. Obtułowicz $\cdot$ E. Czarnobilska

Department of Clinical and Environmental Allergology, Jagiellonian University, Medical College, Krakow, Poland

e-mail: dorota.myszkowska@uj.edu.pl

D. Myszkowska · E. Czarnobilska

Centre of Clinical and Environmental Allergology,

University Hospital, Krakow, Poland

M. Kostrzon

'Wieliczka' Salt Mine Health Resort, Wieliczka, Poland

J. Kędzierska · M. Namysł · M. Zagórska

Microbiology Unit, University Hospital, Krakow, Poland

A. Stanisz

Department of Bioinformatic and Telemedicine,

Jagiellonian University, Medical College, Krakow, Poland 